\title{
The Dynamics of Anti-Government Protest in Ethiopia from 2015 to 2018: From Hidden to Public resistance
}

\author{
Girma Mekonnen \\ MSC in Governance and development from Antwerp University, Belgium \\ MA in peace and security studies from Addis Ababa University, Ethiopia \\ Lecture, Department of Civics and Ethical studies, Debre Markos University, Ethiopia
}

\author{
DOI: $10.7176 / \mathrm{IAGS} / 72-01$ \\ Publication date:May $31^{\text {st }} 2019$ \\ Introduction
}

The past three years, anti-government protests in Ethiopia revealed that the country is moving from rising narratives to civil unrest. The civil unrest mainly emanates from the official state discourse of 'democratic developmental state', revolutionary democracy and other competing narratives (Branch and Mampilly, 2015). To facilitate a systematic paradigm moves from the democratic transition to economic development, the developmental state narratives become the official ideology of the state (Abbink, 2017; Allo, 2017). Following the disgraceful 2005 election where opposition political parties won major urban areas in including the capital city of Addis Ababa (Lefort, 2007), the Ethiopia People Revolution Democratic Front (hereafter EPRDF) introduces many political and economic reforms to restore its legitimacy.

For many observers, the EPRDF's thriving development narratives, however, depoliticize society, widen social gaps, justify violent repression, and entrench 'ritual' power. Besides, Elites governing narratives extend, legitimize, and sustain a defacto power of the government. (Allo, 2017; Di Nunzio, 2015). Failure to comply rules creates we-they nature of relationship and above all the state politicisation of megaprojects results create an "otherness" of those who do not support such mega projects (Allo, 2017; Lefort, 2007). Finally, the open antigovernment protest began in 2015 and continued until 24 March 2018.

This paper, therefore, discusses the dynamics of power relation between the government and protesters based on Scott conceptual analysis of 'domination and art of resistance' which reveals how elite complex domination strategies pushed subordinate groups to develop resistance strategies. Scott has also reformulated the sources of resentment, driving us to look beyond points of open conflict to social spaces where different ideas and thoughts are created.

For Scott (1990, P. 70) " [the powerful] ... have a vital interest in keeping up the appearances appropriate to their form of domination. Subordinates, for their part, ordinarily have good reasons to help sustain those appearances or, at least, not openly to contradict them'". These two social realities have implication for the study of power relations. Study protest from this perspective also helps to understand the underlying problems of power relation before the eruption of open protest. The 2015 anti-government protest perhaps discloses the rationality of conformity and elite's strategies of domination. Therefore, analysing this social space and underlying power relation offers different perspectives of resistance to imposed domination which is the desired objective of this study.

\section{Significance and Justification of the Study}

The Political crises in Ethiopia are mostly associated with the conflictual nation-building process. Clapham (2009, p. 181) states that "[c]rises of governance in Ethiopia are embedded in the long uneven history of the Ethiopian state itself', When the Ethiopian People's Revolutionary Democratic Front, EPRDF) control power, the same competing national issues become the sources of conflict. For its long history of the central government, "ruling Ethiopia has never been easy"' (Clapham, 2009, p. 181).

The EPRDF control political power in 1991 after seventeen years of armed struggle to end the military regime led by Mengistu Hailemariam. The EPRDF reshuffle the structures of the military regime (1974-1991), to be replaced by a new administrative map of the country based on linguistic/ethnic criteria. It also rejected the military regime's command economy and announced a 'free market-oriented economic policy (Clapham, 2009; Merera, 2011). But later this economic system modified into the developmental state.

Once control the state, EPRDF promised to the country and its people multiparty democracy, respect for human rights, a decentralized system of governance and a liberalized economy. To make true its promises, it proclaimed a Charter for the Transitional Period that enumerated the various freedoms, policies and rights to come (Merera, 2011). However, there is a huge gap between popular expectation and the reality on the ground. Perhaps, many observers argue that the degree of press freedom at the beginning of the EPRDF era was relatively better than this day.

In relation to this, Scott (1990, p. 50) also states that "the dominant can create an appearance that approximates what, ideally, they would want subordinates to see'. Elite vowed because they want to build their 
'personal cult' through false appearance and empty narratives. For many observers too, elections prove the authoritarian nature of the EPRDF (Abbink, 2017; Arriola, 2016; Branch \& Mampilly, 2015; Lefort 2007). For instance, Lefort (2007, p. 262) argues that " [ $t$ ]he party had given priority to the rural population '...] exercised a strong hold on rural areas through its dominant position and a control apparatus that it could resort to if necessary",

Other still states that EPRDF made a paradigm shift from legitimacy by election (democratic transition) to legitimacy through economic development (Abbink, 2017; Branch \& Mampilly, 2015). Following the 2005 election, election campaign primary targets urban youth. Policies and strategies primary designated to mobilize youth. According to Di Nunzio (2015), elites deliberately target urban youths to seek obedience or to defuse opposition. Small-scale enterprise policies systematically utilized to seek affirmation or otherwise to neutralise youth in addition, (Di Nunzio, 2015).

Consecutive Human Right Watch reports and Freedom House Reports reveal the authoritarian tendencies of ERPRDF. Abbink (2017, p. 306) also argues that questioning the level of democratisation in Ethiopia no longer valid. Rather, "the approach to Ethiopian politics should be [...] observing the political self-perception of the party or elite in power and its encompassing mobilisation strategies and recognising a political culture of deference and fear'" (p. 306).

Given the political development in Ethiopia for the last two decades, this study explores the dynamics of protest and domination in the country from various perspectives. Perhaps, most analysis reveals that the more states become authoritarians, the easier to interpret the hidden transcripts of subordinate groups (Lukes, 2005; Scott, 1990).

\section{Materials and Methods}

Methodologically, the study uses a qualitative approach to develop the theoretical framework and to analyze the finding sections. It is commonly known that qualitative research design is a panacea to explore and understand the multiple and complex realities of societal problems in natural settings (Creswell, 2008). It also gives maximum freedom and flexibility to the researcher to interpret the problem from various perspectives (Creswell, 2008). In addition to this, analysing the dynamics of protest, domination and resistance and the problem of ethnicity, nation and nationalism by itself requires a holistic understanding of the complex historical process and associated discourse in various context. Accordingly, this paper uses existing theories, empirical studies, various perspectives and other academic journals.

\section{Theoretical Perspectives and Literature Review}

The paper begins with reviewing Scott's (1990) hidden transcript and public transcript of dominant groups and subordinates' groups and other related works of literature. According to Scott (1990, p. 33), "conformity is tactical it is surely manipulative". Subordinates conform and obey "not because they have internalized the norms and values of the dominant group or are resigned to their status, but because the structure of surveillance, punishment and reward makes it prudent for them to comply" (Scott, 1990, p. 193). In the absence of the dominant groups, subordinates actively engage in resistance through language and disguised activity to avoid detection (Scott, 1990).

In the same vein, dominant elites are able to use the threat of violence to enforce public conformity to rituals which celebrate their power and to extract performances which appear to offer support for the status quo and through which they can extract material and social resources. However, the public conformity of subordinates in such situations does not reflect an inner consent; indeed, the coercive nature of power relations tends to preclude these relations being seen as legitimate by subordinates (Scott, 1990).

Scott (1990) also states that the hidden transcripts of the subordinates are often a site in which elite power is questioned and rejected and resistances are rehearsed or even acted out. When revolts and revolutions occur, and when individuals defy the powerful due (for instance) to anger or drunkenness, the public defiance is usually a realisation of what has been rehearsed in the hidden transcript (Scott, 1990). There is, therefore, an entire field of 'infrapolitics' consisting of the attempts of subordinates to construct and defend such spaces and attempts of the elites to close them down and consisting also of attempts by each side to alter the balance of forces and skew the public transcript in the direction of its own conceptions (Scott, 1990).

Scott has introduced or promoted a number of new ways of thinking about power relations. Contrary to our common understanding protest as "a time when the unpredictable, unknown and unforeseen suddenly take centre stage", , Scott (1990) analysis of power relation help us to understand "the often-fugitive political conduct of subordinate groups" (p. xii). Based on the different case studies, Scott (1990 p. xii) examines "contradictions, tensions, and imminent possibilities". The relevance of his work is therefore by no means limited to Asia-Pacific Studies. It provides an important new paradigm in terms of which we can conceptualize

\footnotetext{
${ }^{1}$ Arendt cited in Branch\& Mampilly (2015, p. 10)
} 
the experience and agency of domination (Lukes, 2005).

Scott has reformulated the sources of resentment, driving us to look beyond points of open conflict to social spaces where different ideas and thoughts are created. Therefore, analysing this social space and underlying power relation offers different perspectives of resistance to imposed domination (Lukes, 2005).

\section{Definitions and Terminologies}

Domination and Resistance

Domination, for Scott (1990), is appropriation and extraction. It is the process where "[d]ominant elites extract material taxes in the form of labor, grain, cash, and service in addition to extracting symbolic taxes in the form of deference, demeanour, posture, verbal formulas, and acts of humility" (Scott, 1889, P.188) but, less willing to acknowledge the power of dominants elite. Subordinate groups resort high level of secret resistance to counter exploitative extraction and domination (Scott, 1990). He argues that "the greater the power exercised over them, the more incentive subordinates have to foster the impression of compliance, agreement, and deference" (Scott, 1990, p. 90).

For Scott (1990) resistance to domination involves strategies to counter appropriation. Such strategies target both 'material and symbolic exploitation'. Resistance is not only the struggle for material and power resources, but also for the struggle to reshape identity, culture, history, and ideology. Scott's s conceptualization of domination also extrapolates existing power relations in authoritarian states.

\section{The Public transcripts}

According to Scott (1990), the public transcript is the visible power relation between dominant groups and subordinate groups. It contains the formal and official exchanges between the dominant and subordinate groups, as well as the ideology that serves to legitimate existing power relations. The public transcript also expresses the views of those in control, while it marginalizes and silences contradictory perspectives of subordinates. In a similar vein, dominant groups exercise power by privileging its own discourse, and by controlling the behaviour of subordinate groups. Public articulations of mastery and subordination, including the natural and rational justification for unequal power relations, comprise much of the public transcript (Scott, 1990).

Scott (1990) identifies some salient attributes of public transcripts. First, public transcripts are less likely to tell us the broader picture of power relation. As Scott $(1990$, p. 2) "[i]t is frequently in the interest of both parties to tacitly conspire in misrepresentation". Second, Scott (1990, p. 3) argues that the extra discrepancy of power between dominant groups and subordinate groups and the more subjective it exercised the more "the public transcript of subordinates will take on a categorised, ritualistic cast". Third, sequencing is a matter between the public transcripts and the subordinates. For Scott (1990) the tactical smile, consent, conformity of the subordinates is an expression of grievance and revenge.

The most fundamental question in the public transcript is how to know whether the performance is genuine or not. Based on Scott (1990, p. 4) argument it is difficult to know the authenticity of the performance " [w]ithout a privileged peek backstage or a rupture in the performance we have no way of calling into question the status of what might be a convincing but feigned performance"'.

\section{The Hidden Transcripts}

Despite superficial interactions, subordinates neither agree nor comply with the public transcript. Hence, "the hidden transcript is, for this reason, the privileged site for nonhegemonic, contrapuntal, dissident, subversive discourse" (Scott, 1990, p. 25). It contains evidence to challenge dominant groups claims to legitimacy and it discursively negates the hegemonic messages of the public transcript. Resistance expressed through the hidden transcript is an attempt by subordinates to minimize appropriation, assert their dignity, and refute the ruling ideology (Scott, 1990).

Like public transcript, Scott (1990) identifies three fundamental characteristics of the hidden transcript. First, the hidden transcript performed in restricted "social site and to a particular set of actors" (p. 14). In other words, "each hidden transcript, then, is actually elaborated among a restricted 'public' that excludes-that is hidden from certainly specified others"' (Scott, 1990 p. 14). Second, subordinate groups take whole range actions under the umbrella of the hidden transcript: "speech acts [...] poaching, pilfering, clandestine tax evasion, and intentionally shabby work for landlords" are components the hidden transcript (Scott, 1990, P.14).

On the other hand, dominant group "hidden transcripts might include clandestine luxury and privilege, surreptitious use of hired thugs, bribery, and tampering with land titles" (Scott, 1990, p. 14). Third, the boundary between the hidden transcript and the public transcript is an area of a bone of contention and source of disagreement.

In a nutshell, Scott (1990, p. 14) provides a reasonable assessment of the public transcript. He further argues that "[w]e do not wish to prejudge, by definition [...] what is said in the face of power and what is said behind its back. In other words, it is not easy to judge power relation. 


\section{Infrapolitics}

Infrapolitics include strategies designed to disguise the political message, the messenger, or both. The hidden transcript is itself the object of repression because it undermines the authority of those in power and threatens existing power relations (Scott, 1990). It survives only in disguised discourse or in sites sequestered from the surveillance of dominant group members. It is politics of disguise and anonymity, that which Scott calls infrapolitics (Scott, 1990).

For Scott (1990), infrapolitics include linguistic strategies as well as low profile behavioural strategies. Political subversion is disguised through linguistic strategies, activities, behaviours, and sets of practices that articulate a great deal about the power relations between dominants and subordinates. Furthermore, infrapolitics and the hidden transcript are designed to be invisible to the unacquainted and uninitiated or to be so ambiguous, innocuous or indirect as to be capable of multiple interpretations, particularly interpretations that appear to support the hegemony of the public transcript. Although conducted and articulated within public view, the meaning of this political discourse or behaviour is often discernible only to those with intimate knowledge of the folk culture of the subordinate group (Scott, 1990).

Scott (1990, p. 166) further explains that "one of the most effective and common ways subordinates may express resistance is by embedding it in a larger context of symbolic compliance' Indeed, symbolic compliance is key to infrapolitics because although members of the dominant groups may be unable to interpret the behaviour of subordinates, they do suspect seditious intent, and for this reason, they attempt to control the physical locations and discursive spaces of subordinates (Scott, 1990).

\section{Saturnalias of Power}

Scott (1990, p. 204) characterize saturnalias of power as "[t]he first open statement of a hidden transcript". He also creates a distinction between "a practical failure to comply and a declared refusal to comply [the] former does not necessarily breach the normative order of domination; the latter almost always doe Saturnalias of Power" (Scott, 1990, p. 204). It is a stage where compliance to arbitrary rule openly questioned and criticised. The danger of this stage is that the violent expression defying may exacerbate identity politics. If the existing security fails to act in professionally, dangerous incidents may cost human lives.

\section{Results and Discussion}

\section{The EPRDF's Public Transcript and the working of domination}

For the EPRDF'S elites, economic growth alone is enough reason "to stay in power, unquestioned and "uncriticisable" (Abbink, 2017, p. 309). Thus, the primary source of EPRDF legitimacy is economic growth, not a democracy. From central to the local level, women, civil servants, youth, students, teachers, traders etcetera immobilised into 1 to 5 association. Every weekend they discuss various affairs including the development progress made of the EPRDF (Lefort, 2007 \& 2012).

Furthermore, the EPRDF organize regular gathering, meeting, celebrities, and other tactics either to evaluate its popular acceptance or assess the perception of the community towards the government. To win the heart and minds of the people the EPRDF designed a policy of developmental actors. In relation to this, Lefort (2012, p. 681) argues that 'smallholder farmers, recruited both as 'model farmers' to become the engine for the growth [...] and as members of the ruling party'. However, as Scott (1990, p. 46) stated [m]ost discursive affirmations are [...] not designed as mere displays". They have the broader purpose of sustaining domination.

Controlling people through 'draconian law' is another source of domination for the EPRDF. Human Right Watch $(2018$, p. 1) reports revealed that "[b]road restrictions on civil society and independent media, the decimation of independent political parties, harassment and arbitrary detention of those who do not actively support the government, severely limited space for dissenting voices"'. The anti-terror proclamation also gave an extended mandate to police and intelligence office to conduct what Scott (1990, p. 47) call it "silent monitor", on people including their own party members. The country is also recognised as 'authoritarian states' in the Freedom House index.

The 2015 election in Ethiopia was another EPRDF discursive strategy to consolidate its grip of power. The death of the late prime minister, Meles Zenawi in 2012 creates a power vacuum for some days and political uncertainties. But, the 'revolutionary democracy' narrative creates strong party discipline. The 'developmental state' produce legitimacy. Ethnic politics of the party creates nation-building narratives (Abbink, 2017, Allo, 2017; Lefort, 2012). Many people warmly applause and support the party program either to escape from punishment or maximize personal gains (Abbink, 2017). EPRDF also deliberately targets urban youths to pledge obedience and defuse opposition. Small -scale enterprise become the ideal 'expressive strategy' of EPRDF to seek affirmation or otherwise to neutralise youth (Di Nunzio, 2015).

The outcome of the election for the EPRDF was more than expected. The EPRDF for the first-time secure 100 percent parliamentary seats with 93 percent voter turnout. It was the first electoral victory for the party in the absence of the late prime minister, Meles Zenawi. Abbink (2017, p. 305) provides a reasonable assessment in his 
own word:

"It was widely expected that the EPRDF would win with a 'very wide margin'. The ubiquitous presence of the party in Ethiopian life, and its organisational machine with virtually complete control of the media, Internet, and other means of communication made sure of this'.

In nutshell, the question of representation, right of peaceful demonstration, freedom of expression, civic right and political freedom curtailed though it legally endorsed in the state constitution (ICG, 2009). Rather than giving legal solutions for citizen questions, EPRDF prefers a political solution with a double standard. EPRDF also enact contradictory national rule and regulation that structurally limit the capability of individuals. Many agree that EPRDF's 'carrot and stick' politics centred on enriching personal power.

\section{The dynamics of the Amhara and Oromo Protest}

The Oromo protests began in November 2015 following EPRDF's legislation of the Addis Ababa Master Plan, which called for the integration of the capital's territorial boundaries into the adjacent territories of Oromo lands. For the Oromo, however, decades of land grabbing meant this was already a step too far (Allo, 2017). As of July 2016, the protests have been spreading into the Amhara region, home to the second largest ethnic group in the country. Protesters, who identify themselves as ethnic Amhara, clashed with police during the demonstrations, labelled as the biggest anti-government unrest Ethiopia has witnessed in recent history (The Ethiopian Reporter, 2016).

Perhaps, the two largest ethnic groups protests deferred from the factional disputes that have periodically erupted within the governing party. The protests have deeply-rooted political, ideological, economic and cultural causes, including the increasingly centralized nature of decision-making in a one-party state, discriminatory allocation of resources and benefits of economic growth, and the weakening of all the political opponents of the regime (Lefort, 2018).

The government has publicly proclaimed that the country is moving toward democracy - albeit slowly given the many challenges it faces - but the evidence from World Governance Indicators shows that civil and political rights have been deteriorating in Ethiopia, not improving. Ethiopia's democratic transition is not merely stuck, it is retreating (Abbink, 2017). Therefore, a combination of rage, disillusionment, frustration, material deprivation pushed protestors to challenge the incumbent government. The Human Right Watch boldly stated that the EPRDF has "hundred ways of putting pressure"' to control its own people (Human Right Watch, 2009, p.1).

\section{The 'Wax and Gold' tradition in Amhara and its Hidden transcript}

In Ethiopia, disguising feelings run deep. It is entrenched in the very old history of the country Scott $(1990, p$. v) also quotes Ethiopian proverb as "[w]hen the great lord passes the wise peasant bows deeply and silently farts". It is inviable ways denouncing the legitimacy of elites. Opposition figures also relied on the tradition of disguise to go undetected by censors, but it meshes deeply with culture too (Levine, 1965). In fact, "resistance to ideological domination requires a counter ideology-a negation-that will effectively provide a general normative form to the host of resistant practices invented in self-defence by any subordinate group" (Scott, 1990, p. 118). Infrapolitics and the hidden transcript are designed to be invisible to the unacquainted and uninitiated or to be so ambiguous, innocuous or indirect as to be capable of multiple interpretations, particularly interpretations that appear to support the hegemony of the public transcript. Although conducted and articulated within public view, the meaning of this political discourse or behaviour is often discernible only to those with intimate knowledge of the folk culture of the subordinate group (Scott, 1990).

The Wax and Gold traditions in the country is a national form of poetry, semna werk ('wax and gold'), dedicated to doublespeak. The idea is that the greatest stylishness consists of compressing meaning into the fewest words possible, layering in hidden messages. In the poetry, the wax is the cover - the apparent and meaning that melts away to reveal the true, valuable meaning. The "gold" hidden in the couplets regularly offers disguised insults - mostly in the direction of political elites. It mostly is an expression of a way of thinking (Levine, 1965; Mohammed, 2010).

In nutshell, the state security apparatus strong and stand for primarily for regime security. Within such restrictive, the cheapest commodity available for subordinates is to display pseudo loyalty and give a warm applause for elite performances. Perhaps, critics call Ethiopia a police state to indicates the authoritarian nature of the EPRDF. In this context, what protesters articulated for the last three years was EPRDF's domination and design their own informal networking to push the party to take measures.

The Amhara and Oromo ethnic groups particularly play a pivotal role in rehearsing effective art of resistance against the ruling party. Through this informal networking (Oro-Mara), they managed to control and regulate the daily behaviour of the people. When the protest later intensified, gossip, gesture and defying has been witnessed in a various social setting: coffee ceremony, wedding, funerals, music, myth, tradition, poet. This kind of hidden transcript and infrapolitics has transformed the power relation between EPRDF and protesters. 


\section{Nationalistic Music: The infrapolitics of protesters}

Music in Ethiopia political struggle can be seen as a liberating, which uplifts, inspire and shows the way for the people to take part in the struggle against injustice and inequality. Through music, artists have revealed and developed their social political and moral identities (Allo, 2018). Historically, songs and musical puns, particularly those nationalistic ones, has been inspired and mobilised people to defend their nation from foreign aggressors, which was often evident in Ethiopia history.

Such songs are also promoters of and means for instilling a love of nation in the hearts of citizens. Songs also serve to tell stories of the past. For example, Teddy Afro's (well-known Ethiopian Musician) recent album Ethiopia - can be an example here. Teddy also remembers Emperor Tewodros and the history of Gondar surrounding his time. Teddy also has an album titled "Tikur Sew" - Black Lion, where he praised Emperor Menelik II and the nobility around him down the line of hierarchy and the roles they had played in defending their country.

Moreover, On 10 December 2017, the capital Addis Ababa staged the biggest Oromo concert it had ever seen. It was held to raise humanitarian funds for the over 700,000 Oromos displaced by violence in the east. But the event held a much deeper significance too. It was not only the most symbolic, defiant and spectacular Oromo concert ever broadcast live by Oromia Broadcasting Network (OBN, regional media). It also featured an unprecedentedly large number of senior government officials, a sign of the slow but tectonic shift taking root in Ethiopian politics (Allo, 2018).

In the concert, a diverse cast of artists performed, leading up to the colourful set by Haacaaluu Hundeessa. As the performance progressed, Haacaaluu escalated tensions, asking the audience how long they would have to wait for freedom. He lamented the absurdity of a marginalised majority, criticised a rigged system, and expressed his yearning for unity, peace, and justice (Allo, 2018).

According to Allo (2018), Haacaaluu challenged the audience and the Oromo leadership in the gallery, which included Abiy Ahmed, to make bold moves befitting of the Oromo public and its political posture. He urged his audience to look in the mirror, to focus on themselves, and decolonise their minds. We are, he said, closer to Arat Kilo, Ethiopia's equivalent of Westminster, both by virtue of geography and demography (Allo, 2018).

\section{Saturnalias of Power of the Protesters: Down Down the EPRDF!}

Scott (1990, p. 203) defines the last stage of resistance as "a declared refusal to comply". Hence, despite the government had tried to curb the protest through various security measures including a state of emergency, protesters in both regions escalate into violence. And, they publicly denouncing repressive laws including; demand the releases of political prisoners, singer, students and other innocent people. They publicly chant down EPRDF! down EPRDF!

It was like "symbolic declaration of war", particularly in Amhara and Oromia regions. According to The Guardian (13 March 2018), "[a]s the protest has grown in confidence in recent years, so the role of the [Qeerroo and Fano] in orchestrating unrest has increasingly drawn the attention of officials". However, the danger of 'public declaration of insubordination' (Scott, 1990) was evident during the last two years protest in Ethiopia. Identity politics, arbitrary looting and competing intersect of various groups exacerbate the political crisis.

\section{Conclusion}

The paper has shown that the sources of resentment, driving us to look beyond points of open direct conflict to social spaces where different ideas and thoughts are created. Hence, analysing this social space and underlying power relation offers different perspectives of resistance to imposed domination particularly in authoritarian states.

Besides, Scott's conceptual framework of domination and the hidden transcript is relevant to analyses the offstage power relation and its operation in authoritarian states. Unlike accidental and ill organizes protests, resistance expressed through the hidden transcript systematically attract wider populace. Everyone has power and the dichotomy of powerful and powerlessness is less meaningful. The power of subordinate groups become visible when they began to resist domination.

The analysis of Ethiopian protest suggests that reliance on military and security measures to quell protesters have proven futile when resistance to domination waged through the hidden transcripts. Furthermore, the case study revealed that the EPRDF has become optionless than transferring its power to the more progressive young prime minister Abiye Ahmed. The protests also indirectly the newly elected prime minister towards greater democratic space and national reconciliation. If Ethiopia's people all took to the street at once, the government would unable to contain the protest.

The study also shows that economic performance does not equal democracy and civil rights. The massive popular protest that broke out in the two largest ethno-regions of the country is the result of EPRDF entrenched authoritarian rule. 


\section{References}

Abbink, J. (2017). Paradoxes of electoral authoritarianism: the 2015 Ethiopian election as hegemonic performance. Journal of Contemporary Africa Studies, 35(3), 303-323. doi: $10.1080 / 02589001.2017 .1324620$

Allo, A. (2017) Protests, terrorism, and development: on Ethiopia's perpetual state of Emergency, Yale Human Rights and Development Law Journal,19(1): http://digitalcommons.law.yale.edu/yhrdlj/vol19/iss1/4

Arriola, L, R. \& Lyons, T.(2016). The 100\% Election. Journal of Democracy,27(1), 76 88, Retrieved from https://www.journalofdemocracy.org/sites/default/files/Arriola-27-1.pdf

Branch, A. \& Mampilly, Z. (2015). Africa uprising: protest and political change. London: Zed Books

Clapham, C. (2009). Post-war Ethiopia: The Trajectories of Crisis, Review of African Political Economy, 36(120), 181-192, doi: 10.1080/03056240903064953

Di Nunzio, M. (2014). Do not cross the red line: The 2010 general elections, dissent, and political mobilization in urban Ethiopia, African Affairs, 113(452), 409-430. doi: 10.1093/afraf/adu029

Di Nunzio, M. (2015). What is the alternative? Youth, entrepreneurship and the developmental state in urban Ethiopia. Development and Change, 46(5), pp. 1179-1200. doi: 10.1111/dech.12187

Girma, M. (16 November 2011). Whose Meaning? The Wax and Gold Tradition as a Philosophical Foundation for an Ethiopian Hermeneutic, 50, 175-187, doi: 10.1007/s11841-010-0201-9

Human Right Watch. (2009). Ethiopia "One hundred ways of putting pressure": freedom of expression and association in Ethiopia https://www.hrw.org/sites/default/files/reports/ethiopia0310webwcover.pdf

Human Right Watch. (2018). Ethiopia: event of 2017. Retrieved from https://www.hrw.org/worldreport/2018/country-chapters/ethiopia.

Lefort, R. (2007). Powers - mengist - and peasants in rural Ethiopia: the May 2005 elections. The Journal of Modern African Studies, 45(2), 253-273.doi: 10.1017/S0022278X0700253

Levine, D, N. (1965). Wax and Gold: Tradition and innovation in Ethiopian culture. Chicago: University of Chicago Press.

Lukes, S. (2005). Power: a radical view (2ed.). Palgrave Macmillan: New York.

Merera, G. (2012) Elections and democratization in Ethiopia, 1991-2010, Journal of Eastern African Studies, 5(4), 664-680, doi: 10.1080/17531055.2011.642524

Scott, J. (1990). Domination and the art of resistance: hidden transcript. Heaven and London: Yale University Press.

The Guardian. (2018). Freedom!': the mysterious movement that brought Ethiopia to a standstill. Retrieved from https://www.theguardian.com/globaldevelopment/2018/mar/13/freedom-oromo-activists-qeerroo-ethiopiastandstill

Worldwide Governance Indicators. (2018). Ethiopia: Voice and accountability. Retrieved from http://info.worldbank.org/governance/wgi/\#reports 